\title{
Are Obese Mothers of Children Aged 1-6 Years Evening-Typed?
}

\author{
Miyo Nakade ${ }^{1,2}$, Miki Hiraoka ${ }^{1}$, Kiyoko Kawasaki ${ }^{1}$, Takuya Uesato ${ }^{1}$, Kai Wada ${ }^{1}$, Milada Krejci ${ }^{3,4}$, Teruki Noji ${ }^{5}$, \\ Nozomi Taniwaki ${ }^{6}$, Hitomi Takeuchi ${ }^{1} \&$ Tetsuo Harada ${ }^{1}$ \\ ${ }^{1}$ Laboratory of Environmental Physiology, Graduate School of Integrated Arts and Sciences, Kochi University, \\ Japan \\ ${ }^{2}$ Department of Nutritional Management, Faculty of Health and Nutrition, Tokai-Gakuen University, Japan \\ ${ }^{3}$ Department of Health Education, Faculty of Education, University of South Bohemia, Jeronymova, Ceske \\ Budejovice, Czech Republic \\ ${ }^{4}$ University of Physical Education and Sport PALESTRA in Prague, Czech Republic \\ ${ }^{5}$ Department of Physical and Health Education, Faculty of Education, Kochi University, Japan \\ ${ }^{6}$ Affiliated Kindergarten, Faculty of Education, Kochi University, Japan \\ Correspondences: Tetsuo Harada, Laboratory of Environmental Physiology, Graduate School of Integrated Arts \\ and Sciences, Kochi University, Kochi 780-8520, Japan. E-mail: haratets@kochi-u.ac.jp
}

Received: September 14, 2013

Accepted: March 17, 2015

Online Published: May 29, 2015

doi:10.5539/ijps.v7n2p121

URL: http://dx.doi.org/10.5539/ijps.v7n2p121

This study was financially supported by Academic Supporting Award by President of Kochi University (2009-2012: To T. Harada), Academic Supporting Award by Dean of Faculty of Education, Kochi University (2008-2009: To T. Harada) and awards from the Japan Society for the Promotion of Science (Award No. 22370089: To T. Harada; Award No. 23-10971 to K. Wada) (2010-2014).

\begin{abstract}
Obesity is a serious problem that is growing in developed countries and many children as short-sleepers have been reported to be obese. However, no studies have been conducted on the relationship between BMI shown by mothers of children aged 1-6 years and their own circadian typology. This study aims to clarify this relationship in Japanese mothers. An integrated questionnaire on diurnal rhythms (including the Diurnal Type Scale constructed by Torsval \& Åkerstedt), sleep habits, meal habits, lighting conditions at night, weight and height was administered to mothers and their children aged 1-6 years. Sixty-two percent of 863 mothers answered the questionnaire for themselves and their children. All the obese mothers (BMI of 28 or more) had MEQ scores of less than 18 and were more evening-typed than non-obese mothers (BMI of less than 28) $(\mathrm{p}=0.02)$. A higher ratio of obese mothers watched TV after 11:00 p.m. $(\mathrm{p}=0.049)$ and used fluorescent lights while watching TV after 11:00 p.m. $(p=0.023)$ compared to non-obese mothers. Obese mothers showed a higher frequency of depression $(p=0.044)$ and tended to have higher frequency of becoming irritated $(p=0.09)$ than non-obese mothers. The children of obese mothers were significantly more evening-typed (Mean $\pm \mathrm{SD}=18.5 \pm 3.6$ ) than those of the other mothers $(21.1 \pm 3.2)(\mathrm{p}=0.018)$. Evening-typed life of mothers with watching mid-night TV would be related to obesity of mothers and children. This study concludes that obese mothers of children aged 1-6 years are evening-typed and the children of obese mothers are also more evening-typed than those of non-obese mothers
\end{abstract}

Keywords: Japanese young children, circadian typology, body mass index of mothers, TV watching at night, obesity

\section{Introduction}

A tremendous number of studies have been reported especially the last couple of years on the relationship between sleep duration and obesity. Nielsen et al. (2011) summarized the 71 recent original studies and seven reviews on the relationship between short sleep duration and obesity and concluded that the relationship is clear in young children and adolescents but not in adults. For example, Drescher et al. (2011) performed the Tucson Children's Assessment of Sleep Apnea follow-up study (TuCASA) cohort study for children aged 10-17 years and concluded that decreased total sleep time and increased caffeine intake and screen time may result in a 
higher obesity risk in the adolescent population. The Council of Communications and Media, The Academy of American Pediatrics (2011) recently warned that children who watch TV late at night have a high risk of obesity, because they have higher-fat diets, drink more soda and have lower calorie expenditure from less exercise (O'Keeffe et al., 2011; Council of communications and media \& The Academy of American Pediatrics, 2011). An epidemiological study on Chinese kindergarten children showed that, compared with children reporting over 11 hours of sleep per night, the odds ratio for childhood obesity was 4.76 (95\% CI, 1.28-17.69) for children with less than 9 hours of sleep, and $3.42(95 \% \mathrm{CI}, 1.12-10.46)$ for children with 9.0 to 9.4 hours of sleep after adjustment for age, sex, and other risk factors (Jiang et al., 2009). In a study on Australian children aged 5-10 years old, Taylor et al. (2012) reported that, compared with children of normal weight, those who were overweight or obese were more likely to spend no time studying, spend more than 2 hours per day in screen-based activity and sleep less than 10 hours per night. Lucassen et al. (2013) recently reported that Eveningness was associated with eating later and a tendency towards fewer and larger meals and lower HDL cholesterol levels in US 119 participants aged 18-50 yrs.

What are the mechanisms for obesity from short sleep duration? One possibility is that a long time awake at night is associated with consuming junk food and sweet beverages while watching nighttime TV (Council of communications and media \& The Academy of American Pediatrics; O'Keeffe et al., 2011). Olds et al. (2011) only reported that late-bed/late-rise Austrian adolescents showed higher BMI scores than early-bed/early-rise adolescents independent of age, sex, household income, geographical remoteness and sleep duration. This suggests that a delayed phase of the circadian clock may be related to obesity in humans. No studies to date have examined the relationship between circadian typology and obesity of mothers with 0 -6-year-old children. This study aims to examine this relationship from epidemiological point of view, as well as to examine the relationship between the obesity of mothers and nighttime TV and lighting.

\section{Participants and Methods}

The data used was collected from responses to questionnaires completed in 2009 by 440 parents (more than $95 \%$ are mothers, response rate: 62\%) of children aged 1-6 (231 girls and 209 boys) in 9 city-run nursery schools and 1 kindergarten affiliated to the Faculty of Education, Kochi University located in Kochi city $\left(33.3{ }^{\circ} \mathrm{N}\right)$. The questionnaires included The Diurnal Type Scale by Torsvall and Åkerstedt (1980) and a revised version for children (Harada et al., 2007), questions on mental health of the children (such as anger and depression) (Harada et al., 2007) and questions only for parents about night lighting (Table 1A) and late night TV watching (Table 1B). The Diurnal Type Scale (Torsvall \& Åkerstedt, 1980) and the version for children (Harada et al., 2007) were used to objectively measure diurnal preference. This part consisted of seven questions: three pertaining to sleep onset, three to sleep offset and one to peak timing of activity. Each question allows for choice (scored from 1 to 4 ) and the M-E score was the sum of the 7 answers. Scores ranged from 7 to 28 , with lower scores representing evening-types and higher scores representing morning-types. The section of sleep habits consisted of questions on sleep onset and offset timings on weekdays and weekends and questions about the quality of sleep such as mood upon falling asleep and waking up. The data was statistically analyzed using $\chi^{2}$-tests, Mann-Whitney U-tests, and Pearson's correlation analysis with SPSS 12.0 statistical software. M-E scores were expressed as means plus or minus the standard deviation (Mean $\pm \mathrm{SD}$ ).

The study followed the guidelines established by the Chronobiology International journal for the conduct of research on human subjects (Portaluppi et al., 2010). Before administrating the questionnaires, each participant (parents or guardians) was given a written explanation that detailed the concepts and purposes of the study and stated that their answers would be used only for academic purposes. After the above explanation, all parents (or guardians) agreed completely with the proposal. The study was also permitted by the kindergarten nurses' committees of the eleven kindergartens which carried out an ethical inspection of the contents of the questionnaire. As the children could not complete the questionnaires themselves, their parents or guardians completed them on their behalf.

\section{Results}

Most of the mothers with a BMI of 28 or more ("obese mothers") had M-E scores of less than 18 and more evening-typed than those with a BMI of less than 28 ("non-obese mothers") (Mann-Whitney U-test: $\mathrm{z}=-3.024$, $\mathrm{p}=0.02$ ) (Figure 1). A higher ratio of the obese mothers watched late night TV (after11:00 p.m.) ( $\chi^{2}$-test: $\chi^{2}$-value $=16.997, \mathrm{df}=1, \mathrm{P}<0.001$ ) (Figure 2) and used fluorescent lamps from sunset to bed time than that of non-obese ones $\left(\chi^{2}\right.$-value $\left.=18.360, \mathrm{df}=1, \mathrm{P}<0.001\right)$ (Figure 3 ).

Obese mothers showed a higher frequency of depression $\left(\chi^{2}\right.$-test: $\chi^{2}$-value $\left.=8.08, \mathrm{df}=1, \mathrm{p}=0.044\right)$ (Figure $\left.4 \mathrm{~A}\right)$ and tended to have higher frequency of becoming irritated $\left(\chi^{2}\right.$-test: $\chi^{2}$-value $=6.44, \mathrm{df}=3$, paper $\left.\mathrm{p}=0.09\right)$ (Figure $4 \mathrm{~B}$ ) 
than non-obese mothers. The children of obese mothers were significantly more evening-typed (Mean \pm $\mathrm{SD}=18.5 \pm 3.6)$ than those $(21.1 \pm 3.2)$ of non-obese mothers (Mann-Whitney U-test: $\mathrm{z}=-2.36, \mathrm{p}=0.018$ ) (Figure 5). A significant positive correlation was seen between the BMIs of 1 year olds and their mothers, but the correlation was reduced for children aged 4 years old (Figure 6).

Table 1. Questions and answers about night lighting (A) and late night TV watching (B) for parents (mostly mothers)

\begin{tabular}{ll}
\hline Question A & What kind of lighting do you use between sunset and bedtime? \\
(multiple answers are allowed) \\
(1) Fluorescent light on the ceiling or walls of the room, \\
(2) Incandescent light or other kind on the ceiling or walls of the room, \\
(3) Fluorescent lamp stand on the desk, \\
(4) Incandescent lamp stand or other kind on the desk, \\
(5) Small incandescent light, \\
(6) Light from the display of a TV or computer, \\
(7) No lighting. \\
Do you watch TV or play video games after 11:00 p.m.? \\
If so, how frequently? \\
(1) Yes (i. everyday, ii. 4-5 times (a week), iii. 2-3 times, iv. 0-1 time(s)) \\
(2) No
\end{tabular}

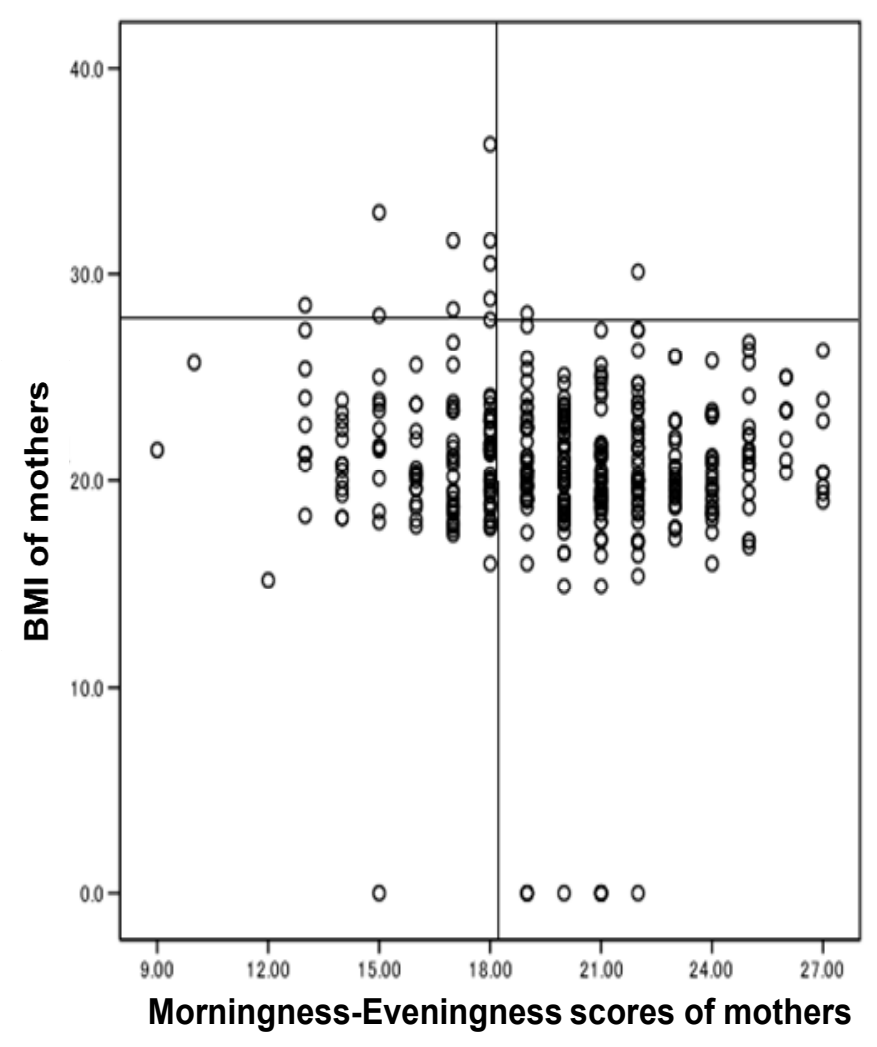

Figure 1. Relationship between BMI and circadian typology of mothers of Japanese young children aged 1-6 years.

Note. Most of obese mothers with a BMI of 28 or more were evening typed with an M-E score of less than 18.0. 


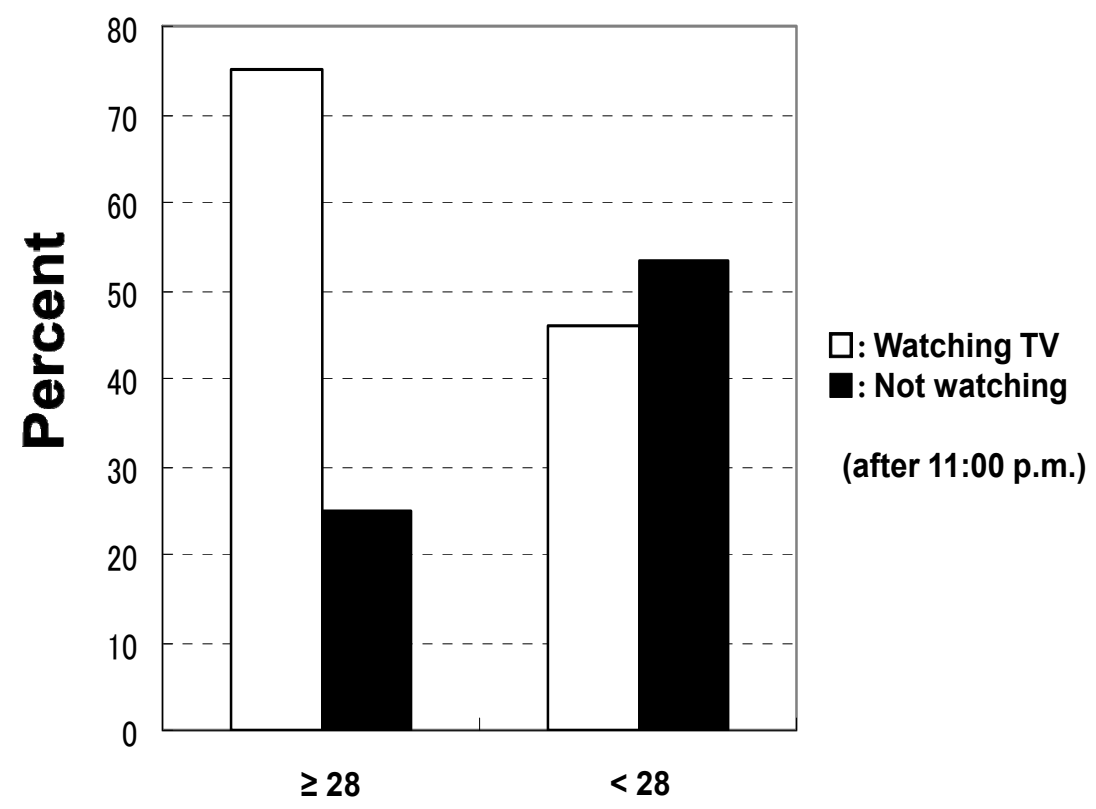

BMI

Figure 2. The relationship between BMI and the ratio of mothers who watch late night TV after 11:00 p.m.

(N)

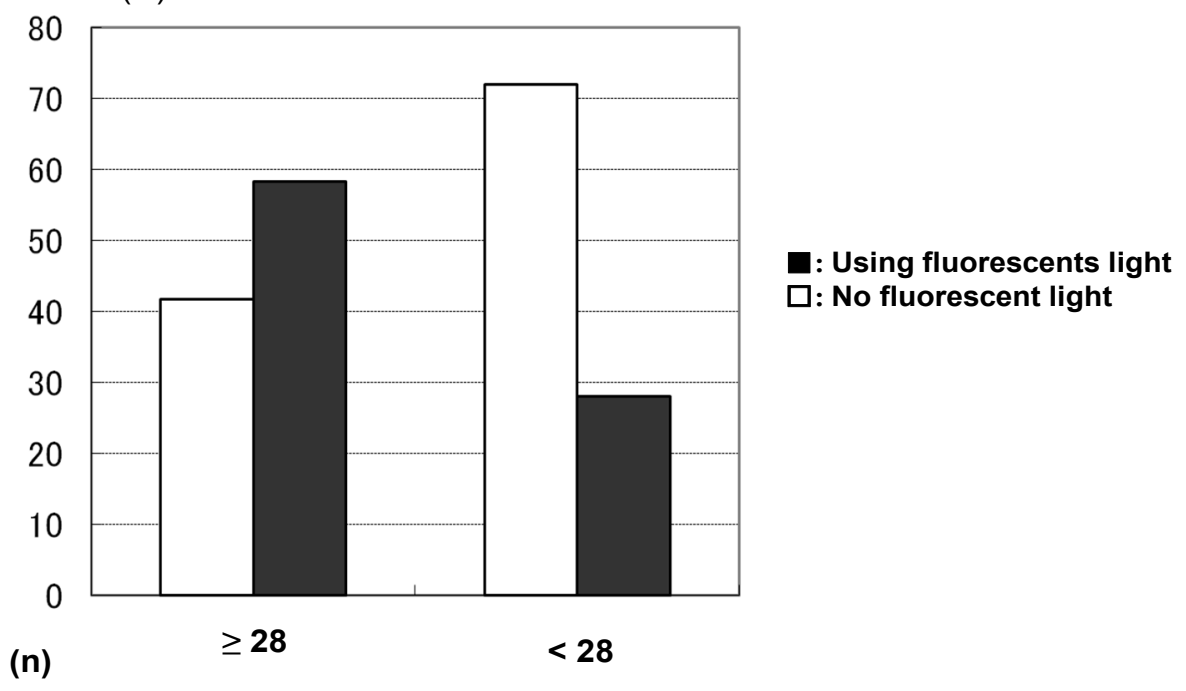

BMI

Figure 3. A high ratio of obese mothers used fluorescent lamps emitting light that includes short wave light with high color temperature, between sunset and bedtime $\left(\chi^{2}\right.$-value $\left.=18.360, \mathrm{df}=1, \mathrm{p}<0.001\right)$ 


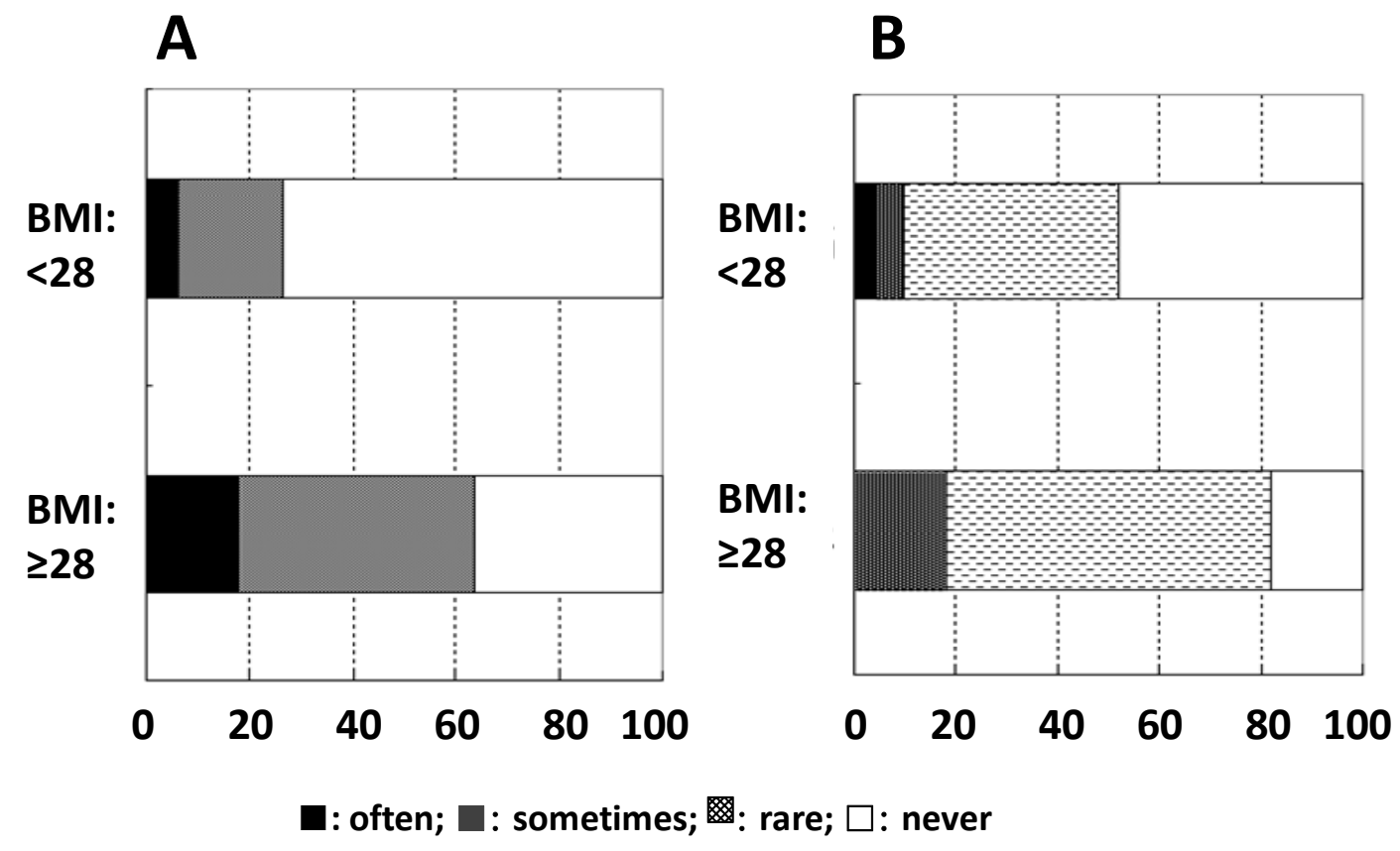

Figure 4. Obese mothers show higher frequency of depression $\left(A: \chi^{2}\right.$-value $\left.=8.075, \mathrm{df}=3, \mathrm{p}=0.044\right)$ and irritation $\left(\mathrm{B}: \chi^{2}\right.$-value $\left.=6.439, \mathrm{df}=3, \mathrm{p}=0.092\right)$

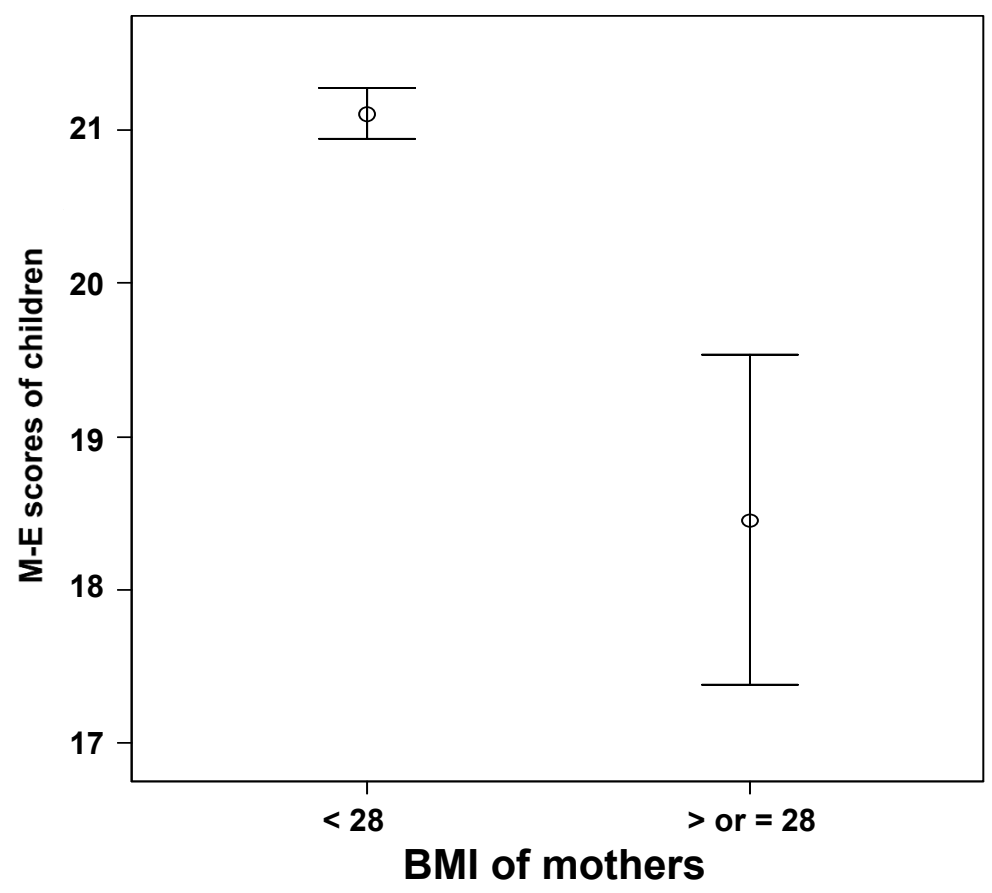

Figure 5. Young children of obese mothers were significantly more evening-typed (18.5 \pm 3.6 : mean $\pm \mathrm{SD})$ than those of non-obese mothers $(21.1 \pm 3.2)$ 

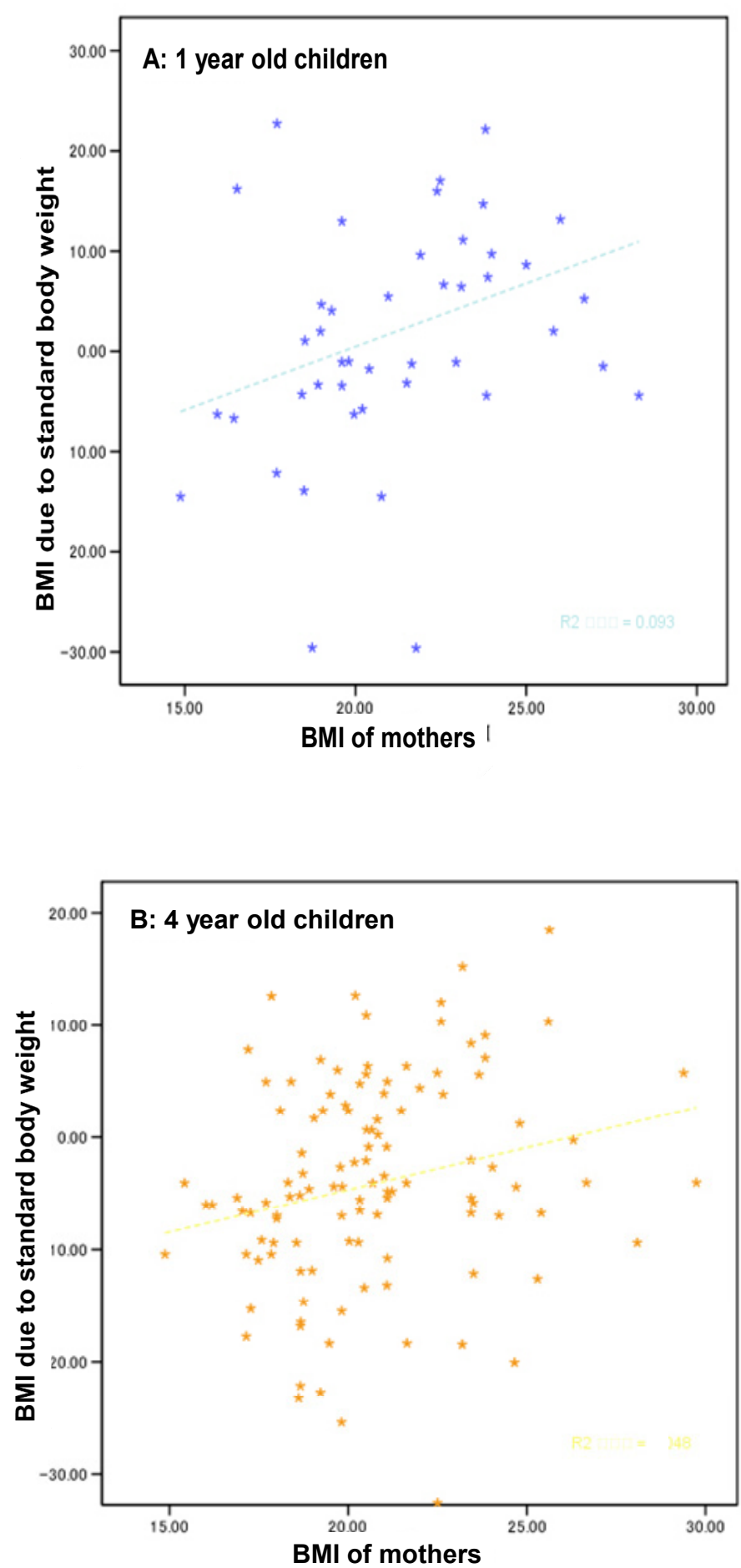

Figure 6. Correlation between BMI shown by young children and that of their mother (Pearson's correlation test: A, 1 year old, $r=0.305, p=0.042, n=45 ; B, 4$ years old, $0.219,0.019, n=115$ )

\section{Discussion}

Evening-typed life for mothers of young children might be related to 24-hour society which is advancing in Japan and includes nighttime services such as late night TV that is broadcast all night on some channels in Japan. A delayed circadian phase of the sleep-wake cycle in these mothers might relate to both their own obesity and 
that of their children. A long time awake at night may be associated with consuming junk food and sweet beverages while watching late night TV. It might be speculated that children may follow the same habits of watching late night TV and having high calorie junk foods and drinks as their mothers. Sasaki et al. (2010) reported that there was no significant correlation between TV watching hours and obesity in Japanese preschool children. However, late night TV watching by mothers could have an impact on their children, because many families in Kochi live in apartments in which a single room functions as both the family bedroom and living room because of low income (3889 thousands yen per year on average, 42.2 years old, 11.4 years carrier in Kochi, $39^{\text {th }}$ rank of 47 prefectures of Japan, 2008) (Nenshu-labo, 2012). In such case, sounds and light emitted from TVs could disturb the sleep of the children. A phase delay of their circadian clock could be promoted by the exposure to blue light at night included in light emitted from TV displays, fluorescent lights and LED (Lockley et al., 2003; Revell et al., 2012).

Another possible mechanism might be the difference in energy expenditure between morning-typed and evening-typed mothers. University students had been phase-advanced by 2 hours by using low color temperature lighting (incandescent light), while those using fluorescent lamps (including short-wave components with high color temperature) as a night lighting did not show such phase advance. The students who used the incandescent light showed 1.5 times of activity amount in an actigraph study throughout the day compared to those using the fluorescent lamp (Harada et al., unpublished).

\section{Conclusion}

A delay of the circadian phase caused by evening-typed life might reduce the activity level and promote obesity due to the reduction of calorie expenditure. Recently, a mutant mouse created by a reduction of the BMAL1 gene that encodes proteins regulating circadian rhythm was reported to show about a $30 \%$ of reduction in muscle force and $40 \%$ reduction in mitochondrial volume (Andrews et al., 2010). A circadian phase of the human circadian clock might be related to skeletal muscle amounts and mitochondria volume via BMAL1 gene also in humans, although there have no studies on such relationship in humans which remains to be studied in the future.

\section{References}

Andrews, J. L., Zhang, X., Mc Carthy, J. J., Mc Dearmon, E. L., Hornberger, T. A., Russell, B., ... Essera, K. A. (2010). CLOCK and BMAL1 regulate MyoD are necessary for maintenance of skeletal muscle phenotype and function. Proceedings of the National Academy of Sciences of the United States of America, 107, 19090-19095. http://dx.doi.org/10.1073/pnas.1014523107

Council of communications and media, \& The Academy of American Pediatrics. (2011). Policy statement-Children adolescents, obesity, and the media. Pediatrics, 128, 201-208. http://dx.doi.org/ 10.1542/peds.2011-1066

Drescher, A. A., Goodwin, J. L., Silva, G. E., \& Quan, S. F. (2011). Caffeine and screen time in adolescence: Associations with short sleep and obesity. Journal of Clinical Sleep Medicine, 7, 337-342.

Harada, T., Hirotani, M., Maeda, M., Nomura, H., \& Takeuchi, H. (2007). Correlation between breakfast tryptophan content and morningness-eveningness in Japanese infants and students aged 0-15 yrs. Journal of Physiological Anthropology, 26, 201-207. http://dx.doi.org/10.2114/jpa2.26.201

Jiang, F., Zhu, S., Yan, C., Jin, X., Bandla, H., \& Shen, X. (2009). Sleep and obesity in preschool children. Journal of Pediatrics, 154, 814-818. http://dx.doi.org/10.1016/j.jpeds.2008.12.043

Lockley, S. W., Brainard, G. C., \& Czeisler, C. A. (2003). High sensitivity of the human circadian melatonin rhythm to resetting by short wavelength light. The Journal of Clinical Endocrinology \& Metabolism, 488, 502-4505. http://dx.doi.org/10.1210/jc.2003-030570

Lucassen, E. A., Zhao, X., Rother, K. I., Mattingly, M. S., Courville, A. B., De Jonge, L., ... Cizza, G. (2013). Evening chronotype is Associated with changes in eating behavior, more sleep apnea, and increased stress hormones in short sleeping obese individuals. PLOS ONE, 8, e56519. http://dx.doi.org/10.1371/ journal.pone.0056519

Nenshu-labo Mean income of labors in Kochi Prefecture, Japan. (2012). Retrieved from http://nensyu-labo.com/ ken_kochi.htm 2012

Nielsen, L. S., Danielsen, K. V., \& Sørensen, S. L. (2011). Short sleep duration as a possible cause of obesity: Critical analysis of the epidemiological evidence. Obesity Reviews, 12, 78-92. http://dx.doi.org/10.1111/ j.1467-789X.2010.00724.X 
O’Keeffe, G. S., Clarke-Pearson, K., \& Council on Communications and Media. (2011). The impact of social media on children, adolescents, and families. Pediatrics, 127, 800-804. http://dx.doi.org/10.1542/ peds.2011-0054

Olds, T. S., Maher, C. A., \& Matricciani, L. (2011). Sleep duration or bedtime? Exploring the relationship between sleep habits and weight status and activity patterns. Sleep, 34, 1299-1307. http://dx.doi.org/ 10.5665/sleep. 1266

Portaluppi, F., Smolensky, M. H., \& Touitou, Y. (2010). Effects and methods for biological rhythm research on animals and human beings. Chronobiology International, 27, 1911-1929. http://dx.doi.org/10.3109/ 07420528.2010 .516381

Revell, V. L., Molina, T. A., \& Eastman, C. I. (2012). Human phase response curve to intermittent blue light using a commercially available device. Journal of Physiology, 19, 4859-4868. http://dx.doi.org/10.1113/ jphysiol.2012.235416

Sasaki, A., Yorifuji, T., Iwase, T., Komatsu, H., Takao, S., \& Doi, H. (2010). Is there any association between TV viewing and obesity in preschool children in Japan? Acta Medical Okayama, 64, 137-142. Retrieved from http://escholarship.lib.okayama-u.ac.jp/amo/vol64/iss2/8

Taylor, A. W., Winefield, H., Kettler, L., Roberts, R., \& Gill, T. K. G. (2012). A population study of 5 to 15 year olds: Full time maternal employment not associated with high BMI. The importance of screen-based activity, reading for pleasure and sleep duration in children's BMI. Maternal and Child Health Journal, 16, 587-599. http://dx.doi.org/10.1007/s10995-011-0792-y

Torsvall, L., \& Åkerstedt, T. (1980). A diurnal type scale: Construction, consistency and validation in shift work. Scandinavian Journal of Work, Environment \& Health, 6, 283-290. http://dx.doi.org/10.5271/sjweh.2608

\section{Copyrights}

Copyright for this article is retained by the author(s), with first publication rights granted to the journal.

This is an open-access article distributed under the terms and conditions of the Creative Commons Attribution license (http://creativecommons.org/licenses/by/3.0/). 